\title{
Retossigmoidectomia com anastomose colorretal e nefrectomia devidos a pólipos adenomatosos, adenocarcinoma retal e carcinoma de células renais em paciente pós-COVID-19
}

\author{
Rectosigmoidectomy with colorectal anastomosis and nephrectomy due to adenomatous \\ polyps, rectal adenocarcinoma and renal cell carcinoma in a post-COVID-19 patient \\ Rectosigmoidectomía con anastomosis colorrectal y nefrectomía por pólipos \\ adenomatosos, adenocarcinoma rectal y carcinoma de células renales en un paciente \\ post-COVID-19
}

Felipe Gustavo Morais Menegassi ${ }^{1 *}$, Lucas do Valle Ciccozzi ${ }^{1}$, Pedro Hidekatsu Melo Esaki ${ }^{1}$, Maria Elisa Alcântara da Cruz¹, Valéria Cardoso Pinto Resende ${ }^{2,3}$, Flávio José Dutra de Moura ${ }^{3}$.

\section{RESUMO}

Objetivo: Dissertar sobre um caso de paciente senil, com câncer colorretal, múltiplos pólipos adenomatosos, tumor renal e COVID-19. Analisar as terapêuticas propostas e a relevância da retossigmoidectomia e nefrectomia como tratamento ao adenocarcinoma retal e carcinoma renal. Detalhamento do caso: Paciente, masculino, 82 anos, admitido em 2019 com crises álgicas abdominais, equimose extensa em membro superior direito, petéquia em lábio inferior, calafrios, diaforese, hematúria e melena. À colonoscopia observou-se lesão retal vegetante, pólipos e diverticulose em cólon. Em junho de 2020 evoluiu com dispneia, febre, fraqueza e mal estar generalizado, confirmando COVID-19 em exames laboratoriais, evoluindo com cura 2 semanas após tratamento. Em agosto de 2020, em nova colonoscopia, observou-se diversos pólipos sésseis e lesão polipoide de $5 \mathrm{~cm}$ em reto. À biópsia, indicado adenocarcinoma retal. À tomografia computadorizada de abdome e à ecografia de abdome total foi identificado tumor renal à direita. Paciente foi então submetido a retossigmoidectomia com anastomose colorretal e nefrectomia à direita. Considerações finais: A colonoscopia ainda é considerada um exame de rastreio excelente para os pólipos intestinais. Com relação ao adenocarcinoma retal, a retossigmoidectomia é considerada um tratamento curativo eficaz. Contudo, a COVID-19 é considerada um fator de risco com alta mortalidade em pacientes com câncer.

Palavras-chave: SARS-CoV-2, Pólipos colônicos, Adenocarcinoma, Ressecção do reto, Nefrectomia.

\section{ABSTRACT}

Objective: To report a case of a senile patient with colorectal cancer, multiple adenomatous polyps, renal tumor and COVID-19. To analyze the proposed therapies and the relevance of rectosigmoidectomy and nephrectomy as a treatment for rectal adenocarcinoma and renal carcinoma. Case details: Male patient, 82 years old, sought a hospital in 2019 with abdominal pain crises, extensive ecchymosis in the right upper limb, petechia in the lower lip, chills, diaphoresis, hematuria and melena. Colonoscopy showed a vegetating rectal lesion, ascending colon polyps and colonic diverticulosis. In June 2020, developed dyspnea, fever, weakness and general malaise, confirming COVID-19 in laboratory tests, cured two weeks after treatment. In August 2020 , the colonoscopy, several sessile polyps and a $5 \mathrm{~cm}$ polypoid lesion in the rectum were observed. Biopsy indicated rectal adenocarcinoma. Renal tumor on the right was identified by computed tomography of the abdomen and ultrasound of the total abdomen. The patient was then submitted to rectosigmoidectomy with colorectal anastomosis and nephrectomy on the right. Final considerations: The colonoscopy is still considered an excellent screening test for intestinal polyps. Regarding rectal adenocarcinoma, rectosigmoidectomy is considered an effective curative treatment. Finally, COVID-19 is considered a risk factor for high mortality in cancer patients.

Keywords: SARS-CoV-2, Colonic polyps, Adenocarcinoma, Rectal resection, Nephrectomy.

\footnotetext{
${ }^{1}$ Centro Universitário do Planalto Central (Uniceplac), Brasília - DF. *E-mail: moraisfelipe029@gmail.com

2 Universidade Federal de Alagoas (UFAL), Maceió - AL.

3 Universidade de Brasília (UnB), Brasília - DF.
} 


\section{RESUMEN}

Objetivo: Hablar del caso de un paciente senil con cáncer colorrectal, múltiples pólipos adenomatosos, tumor renal y COVID-19. Analizar las terapias propuestas y la importancia de la rectosigmoidectomía y la nefrectomía como un tratamiento para el adenocarcinoma de recto y el carcinoma renal. Detalles del caso: Paciente masculino, 82 años, acudió a un hospital en 2019 por crisis de dolor abdominal, equimosis extensa en miembro superior derecho, petequias en labio inferior, escalofríos, diaforesis, hematuria y melena. La colonoscopia mostró una lesión rectal vegetativa, pólipos y diverticulosis en el colon. En junio de 2020, desarrolló disnea, fiebre, debilidad y malestar general, confirmando COVID-19 en pruebas de laboratorio, curándose 2 semanas después del tratamiento. En agosto de 2020, la colonoscopia mostró varios pólipos sésiles y una lesión polipoidea de $5 \mathrm{~cm}$ en el recto. La biopsia indicó adenocarcinoma de recto. El tumor renal de la derecha se identificó mediante tomografía computarizada y ecografía de abdomen. Posteriormente, el paciente fue sometido a rectosigmoidectomía con anastomosis colorrectal y nefrectomía derecha. Consideraciones finales: La colonoscopia es una excelente prueba de detección para pólipos intestinales. En cuanto al adenocarcinoma de recto, la rectosigmoidectomía se considera un tratamiento curativo eficaz. Finalmente, COVID-19 se considera un factor de riesgo de alta mortalidad en pacientes con cáncer.

Palabras clave: SARS-CoV-2, Pólipos del colon, Adenocarcinoma, Resección de recto, Nefrectomía.

\section{INTRODUÇÃO}

Os coronavírus estão presentes na natureza há milhões de anos, existindo consideráveis subtipos de coronavírus coexistindo com numerosas espécies de mamíferos. Algumas espécies de morcegos dispõem inclusive de cepas particulares de coronavírus. Contudo, os primeiros coronavírus foram detectados pelo homem por volta de 1960. A infecção destes vírus é algo relativamente comum nos seres humanos. Assim, as infecções respiratórias podem não ter relevância clínica ou se tornarem síndromes respiratórias graves como a MERS - Síndrome Respiratória do Oriente Médio ou a SARS - Síndrome Respiratória Aguda Grave (JOFFRIN L, et al., 2020).

A COVID-19 é uma identidade diagnóstica relativamente nova. Foi primeiramente constatada em exames laboratoriais a partir de dezembro de 2019. Seus sinais e sintomas mais específicos são cansaço, febre, dispneia, dor torácica e tosse. Por ter neurotropismo já corroborado em literatura, a COVID-19 também leva a anosmia e ageusia em alguns pacientes (MENEGASSI FGM, et al., 2020). A doença é expressada pelo SARS-CoV-2, que é um betacoronavírus com configuração esférica moldada por espículas em sua superfície, dando-Ihe aspecto de coroa. Internamente, possui uma fita de RNA de aproximadamente 100 nanômetros (SINGHAL T, 2020). No atual momento, a World Health Organization aponta 33.502 .430 casos confirmados e 1.004.421 mortos (WORLD HEALTH ORGANIZATION, 2020).

No que diz respeito aos pólipos, pode-se organizá-los em categorias distintas devido ao seu comportamento. Os pólipos adenomatosos são capazes de conceber câncer a nível de tecido intestinal. Em razão disso, estes pólipos são estabelecidos como sendo um estado prodrômico de neoplasia maligna. Esses adenomas podem ser divididos em tubulares, vilosos e tubulovilosos. Existem também os pólipos que não levam ao câncer, como os pólipos hiperplásicos e inflamatórios.

Os pólipos classificados como serrilhados sésseis são abordados como adenomas de grande relevância clínica no contexto de câncer colorretal (CCR). Importante considerar, como fatores de risco para CCR: pólipos > 1cm; mais que 3 pólipos no intestino; displasia. A displasia decorre da injúria contínua, mutações genéticas e desequilíbrio associados ao crescimento e reparo de uma célula (AMERICAN CANCER SOCIETY, 2017).

O CCR verifica-se mediante 3 trajetórias distintas. A primeira acontece via adenoma-carcinoma, sendo responsável por aproximadamente $70 \%$ das neoplasias malignas. A segunda decorre da rara Síndrome de Lynch, sendo responsável por cerca de $5 \%$ dos tumores malignos (TM). A terceira, conhecida como serrilhada, abrange cerca de $30 \%$ de todos os CCRs. Os pólipos serrilhados são mais comumente encontrados na colonoscopia. Esta via ainda possui lacunas no seu entendimento (SINGH R, et al., 2016; SZYLBERG L, et al., 2015). 
O presente trabalho teve como objetivo narrar um caso de paciente com adenocarcinoma retal, pólipos adenomatosos e massa renal direita. $O$ estudo ainda discorreu sobre a retossigmoidectomia com anastomose colorretal e nefrectomia (RACN) como medidas terapêuticas propostas e implementadas no paciente idoso e pós-cura recente pelo COVID-19.

\section{DETALHAMENTO DO CASO}

E.R., masculino, 82 anos, apresentou em maio de 2019 crises álgicas abdominais, equimose extensa em membro superior direito, petéquia em lábio inferior, calafrios, diaforese, hematúria e melena. Paciente exibia história patológica pregressa de hipertensão arterial, labirintite e tabagismo inveterado, com carga tabágica de 68 maços/ano.

À tomografia computadorizada de abdome sem contraste apresentou leve distensão de alças intestinais, espessamento parietal circunferencial em segmento de alça na região hipogástrica, densificação da gordura mesentérica adjacente. Tais achados sugerem processo inflamatório-infeccioso, não sendo possível excluir, no estudo sem contraste, a possibilidade de isquemia intestinal. Espessamento parietal nodular do reto. Nódulo renal à direita.

À endoscopia digestiva alta: registro de pangastrite enantemática leve. À ecografia de abdome total: tumor renal à direita. À colonoscopia: óstios diverticulares esparsos; presença de pólipo séssil de $3 \mathrm{~mm}$ em cólon ascendente; presença de lesão vegetante de aspecto viloso a cerca de $8 \mathrm{~cm}$ da margem anal, medindo aproximadamente $5 \mathrm{~cm}$, ocupando $30 \%$ da circunferência do órgão na parede posterior do reto. À análise anátomo-patológica, adenoma tubular com displasia de baixo grau em cólon ascendente e adenoma viloso com displasia de alto grau em reto.

Em junho de 2020, paciente, 83 anos, evoluiu com dispneia, febre, fraqueza e mal-estar generalizado, confirmando COVID-19 em exames laboratoriais. Paciente foi tratado, evoluindo com melhora dos sintomas e cura da enfermidade após duas semanas de tratamento.

Em agosto de 2020, à nova colonoscopia, fundo de ceco bem visualizado, apresentando duas lesões planas, vinhosas, de aspecto vascular, medindo entre $2-3 \mathrm{~mm}$, sugestivas de angiectasias, sem estigmas de sangramento ativo. Observou-se quatro pólipos sésseis, medindo entre 2-4 mm, de superfície regular, localizados em cólon ascendente, ângulo hepático, cólon transverso proximal e cólon descendente.

Presença de esparsos óstios diverticulares, de base larga e estreita, hipotônicos, distribuídos pelo cólon sigmóide, sem sinais inflamatórios ou estigmas de sangramento. Em reto superior, à cerca de $12 \mathrm{~cm}$ da margem anal, registrou-se lesão polipóide, medindo cerca de $5 \mathrm{~cm}$, de consistência amolecida, com aparente pedículo e vaso calibroso de permeio. A superfície da lesão era enantemática e possuía discretas áreas avasculares que indicavam adenocarcinoma. À biópsia, o diagnóstico anátomo-patológico determinou: adenomas tubulares com displasia leve em cólon, pólipo hiperplásico sem atipias em cólon e lesão glandular com severas atipias, favorecendo o diagnóstico de adenocarcinoma retal bem diferenciado.

Em setembro de 2020 foi realizada RACN à direita. Inicialmente foi realizada a liberação da goteira parietocólica esquerda até ângulo esplênico cranialmente. Ligadura alta de artéria e veia mesentérica inferior. Descida e liberação de peritôneo até reto caudalmente com visualização e preservação dos vasos gonadais e ureter esquerdo. Ligadura dos vasos do mesentério de cólon sigmoide próximo ao cólon. Dissecção circunferencial e isolamento de reto superior e médio.

Secção de reto médio com grampeador linear. Dissecção e secção de sigmoide com confecção de bolsa de tabaco e colocação de ogiva de grampeador circular em coto de cólon. Realizada anastomose colorretal sem tensão com grampeador circular 33mm passado via anorretal. Anéis anastomóticos íntegros. Realizada manobra do borracheiro.

Posteriormente procedeu-se a liberação de goteira parietocólica direita até ângulo hepático. Identificado, dissecado, seccionado e ligado ureter esquerdo. Dissecção renal com identificação e isolamento de artéria e veia renal direitas. Realizada ligadura dupla de artéria e veia renal proximal. Realizada nefrectomia à direita.Rim direito enviado ao anatomopatológico para análise. Resultado: quadro histopatológico do carcinoma de células renais, tipo células claras. Grau nuclear de Fuhrman grau II. Tumor de 3,0x1,5cm. 
Padrão arquitetural tubular, trabecular e áreas focais sólidas. Presença de necrose tumoral comprometendo $30 \%$ da neoplasia. Êmbolos neoplásicos na microvasculatura tumoral não evidenciados. Ausência de infiltração tumoral em ureter, vasos do hilo renal, cápsula e gordura perirrenal. Margens cirúrgicas livres de neoplasia. Estadiamento patológico: pT1a, pNx, pMx. No $8^{\circ}$ dia de pós-operatório, paciente evoluiu em bom estado geral, contactuante, com eliminações fisiológicas, em boa aceitação da dieta, deambulando sem esforço, sono reparador, sinais vitais fisiológicos, com ferida operatória em bom aspecto, limpa e seca. Alta hospitalar no dia 19 de setembro de 2020.

\section{DISCUSSÃO}

O caso em tela retrata um paciente com passado recente de infecção pelo SARS-CoV-2 e em acompanhamento ambulatorial na coloproctologia desde maio de 2019 com diagnóstico de pólipos adenomatosos. Após exames realizados no ano seguinte e após diagnóstico de adenocarcinoma bem diferenciado em reto e massa renal à direita, optou-se por RACN. A condução clínica de pacientes com câncer sempre foi um grande desafio. Contudo, o atual momento de pandemia tornou bem mais complexo o manejo do paciente oncológico. É imprescindível equiponderar os danos de um tratamento oncológico tardio para o paciente portador de COVID-19. Vale salientar que estudos já comprovam a relação deletéria da cirurgia ou quimioterapia associadas ao SARS-CoV-2.

Mesmo que o tratamento para o câncer seja realizado meses antes da infecção pelo coronavírus, estes pacientes tendem a desenvolver quadro clínico mais grave. O paciente oncológico tem 5 vezes mais chances de desenvolver as formas graves da COVID-19 e 8 vezes mais chance de óbito do que a população normal (DENYS A, et al., 2020).

O paciente do presente estudo apresentou quatro pólipos sésseis de $4 \mathrm{~mm}$, superfície regular, localizados em cólon ascendente, ângulo hepático, cólon transverso proximal e cólon descendente. No reto registrou-se lesão polipóide, medindo $5 \mathrm{~cm}$, móvel, de consistência amolecida com pedículo e vaso calibroso de permeio. À biópsia, o diagnóstico estabeleceu adenoma tubular com displasia leve, pólipo hiperplásico sem atipias e lesão glandular com severas atipias indicando adenocarcinoma bem diferenciado.

Pólipos colorretais são protuberâncias do cólon para o lúmen intestinal. Os pólipos podem ser considerados tumores benignos e, em alguns casos, levam ao CCR. Assim, em alguns contextos é necessária a remoção cirúrgica dos pólipos como prevenção do câncer. Um pólipo pode ser dividido em benigno, adenomatoso (ou pré-canceroso) e adenocarcinoma. Ainda é possível agrupá-los em pólipos adenomatosos e não adenomatosos. Os adenomatosos podem ser tubulares, vilosos ou tubulovilosos (AMERICAN CANCER SOCIETY, 2017; NGUYEN LH, et al., 2019).

Além dos 3 tipos de pólipos adenomatosos, ainda existem os pólipos serrilhados que são considerados adenomas devido à sua potencial repercussão no CCR. Estes constituem um grupo distinto de pólipos por levarem ao carcinoma colorretal serrilhado. A via serrilhada é definida pela metilação do DNA e alterações genéticas do BRAF. Os pólipos serrilhados podem ser subdivididos em três grupos: pólipo hiperplásico, adenoma serrilhado convencional e adenoma serrilhado séssil. Dentre os pólipos não adenomatosos há os hiperplásicos e inflamatórios que são mais comuns e não tendem a malignizar (BICALHO LGMF, et al., 2015; AMERICAN CANCER SOCIETY, 2017).

A polipectomia reduz o óbito em aproximadamente $50 \%$ por CCR na primeira década. O CCR verifica-se mediante 3 trajetórias distintas. A primeira acontece via adenoma-carcinoma, sendo responsável por aproximadamente $70 \%$ dos TMs. A segunda permeia a rara Síndrome de Lynch, responsável por cerca de $5 \%$ dos TMs. A terceira, ou serrilhada, abrange cerca de $30 \%$ de todos os CCRs.

Os pólipos serrilhados são um dos pólipos mais comumente encontrados na colonoscopia. Esta via ainda possui lacunas no seu entendimento. A excisão dos pólipos serrilhados tem bom prognóstico na prevenção do CCR. Porém, muitas lesões serrilhadas são difíceis de serem diagnosticadas e nem todas levam ao câncer. Os adenomas serrilhados tradicionais têm correlação definida com TMs. Já os adenomas serrilhados sésseis são mais complexos. Estes são os pólipos que mais levam ao CCR dentro da via serrilhada, contudo são facilmente confundidos com os pólipos hiperplásicos no exame colonoscópico (SINGH R, et al., 2016; NGUYEN LH, et al., 2019). 
A nível molecular do CCR constatou-se o caminho tríplice das lesões benignas até sua malignização. Este caminho tem suporte nas peculiaridades genéticas e epigenéticas associadas das lesões. Foram demonstrados 5 subtipos. A via serrilhada é bem definida nos subtipos 1 a 3 . A instabilidade e estabilidade de microssatélites são correlacionados aos subtipos 1 e 2 . Vale salientar que a instabilidade de microssatélites resulta dos danos continuados a nível de DNA decorrentes de alterações genéticas e epigenéticas que são transferidas entre as células na proliferação celular.

Estas mutações vão sendo geradas nos fragmentos da fita de DNA com recorrência padronizada a cada 1-5 nucleotídeos que foram denominados microssatélites. Os subtipos 1 e 2 são caracterizados pelo fator de hipermetilação das ilhotas CPGs e a alteração do oncogene BRAF. Os subtipos 2 e 3 estão relacionados à alta mortalidade. O subtipo 4 estabelece a etiologia do CCR encadeada à via adenoma-carcinoma tradicional. Este subtipo apresenta baixa instabilidade de microssatélites, oncogenes KRAS e BRAF negativos. O subtipo 5 sinaliza histórico de CCR familiar e câncer por Síndrome de Lynch (SINGH R, et al., 2016; POPOUTCHI P, 2016).

Segundo Nguyen LH, et al. (2019), os adenomas tubulares tradicionais e os pólipos da via serrilhada são os maiores responsáveis pelo surgimento do CCR. O tumor colorretal decorre da renovação constante dos tecidos da mucosa gastrointestinal. O crescimento epitelial acontece somente na base da estrutura tecidual. Contudo, a partir da base, as células oncogênicas vão se proliferando rumo ao lúmen intestinal, interrompendo a diferenciação celular, o reparo na replicação do DNA e as ocasionais apoptoses. Assim, dá-se início aos pólipos adenomatosos que vão adquirindo propriedades displásicas, transmutando o epitélio normal em hiperproliferativo. Por fim, estará gerado um adenocarcinoma.

As manifestações clínicas do CCR podem ser sintomáticas ou assintomáticas. Quando assintomático o diagnóstico de câncer se dá através de exames de rastreio. Porém, quando sintomático, os principais sinais e sintomas apresentados são: dor abdominal, alteração do hábito intestinal, hematoquezia melena, astenia, anemia e perda ponderal (THANIKACHALAM K e KHAN G, 2019).

Em 2015, determinou-se um consórcio de CCR que especificava 4 subtipos. Os critérios são baseados na instabilidade de microssatélites e mutações KRAS, BRAF, PI3KCA (GUINNEY J, et al., 2015). As classes são: CMS1 (MSI-imune), CMS2 (Canônico), CMS3 (metabólico), CMS4 (mesenquimal), com incidência 14\%, 37\%, $13 \%$ e $23 \%$, respectivamente (WIELANDT AM, et al., 2017). Quanto a classificação histológica, a principal forma do CCR é representada pelo adenocarcinoma. As outras formas descritas na literatura são o carcinoma de células mucinosas (PESTANA JSG e MARTINS SFF, 2016).

Uma das principais medidas de redução de mortalidade por CCR é a vigilância colonoscópica, sobretudo quando se tem a capacidade de identificar e ressecar lesões pré neoplásicas. No Brasil existem alternativas de rastreio além da colonoscopia, tais como: pesquisa de sangue oculto nas fezes, sigmoidoscopia flexível a cada 5 anos ou retossigmoidoscopia bianualmente, iniciando-se a partir dos 50 anos (DE MENEZES CCS, et al., 2016; BRENNER H, et al., 2014).

O CCR é o terceiro mais prevalente no planeta. Com relação ao aparelho gastrointestinal, é considerado o mais frequente, principalmente em idosos. Aproximadamente $80-90 \%$ dos pacientes têm diagnóstico tardio, descobrindo a neoplasia já em estágio avançado. Destarte, as diretrizes recomendam rastreio precoce nos pacientes sob suspeita de câncer. Quanto às neoplasias renais, há que se prestar atenção ao seu principal precursor: o carcinoma de células renais. A concomitância de TMs primários é um fenômeno muito incomum. Todavia, nas últimas décadas, cada vez mais tem-se observado um sincronismo desses tumores primários no mesmo paciente (SILVA AAM, et al., 2017).

Os locais de maior incidência de implantação metastática são o fígado, pulmões, linfonodos, peritônio e, raramente, ossos e sistema nervoso central. Devido à drenagem venosa/linfática diferir entre os segmentos colônicos, há uma maior proporção de metástases pulmonares pelos tumores primários de reto distal (drenagem via veia cava inferior) do que nos demais segmentos, que apresentam predomínio de metástases hepáticas devido à drenagem pelo sistema porta. As principais complicações das metátases são hepatomegalia dolorosa, ascite carcinomatosa, disfunção vesical, comprometimento pulmonar e ósseo (THANIKACHALAM K e KHAN G, 2019). 
Com relação aos tumores renais, o carcinoma de células renais $(\mathrm{CaCR})$ apresenta-se como o terceiro câncer mais comum do trato geniturinário, e representa aproximadamente $4 \%$ dos TMs. O subtipo histológico mais comum dessa neoplasia é o CaCR de células claras. A mediana de idade ao diagnóstico é de 64 anos e a incidência desse câncer vem aumentando ao longo dos anos devido à evolução dos métodos diagnósticos e do envelhecimento populacional. No momento do diagnóstico, cerca de $30 \%$ dos pacientes no Brasil apresentam metástases (SOARES A, et al., 2019).

Tradicionalmente, o tratamento para tumores renais localizados (até T2c) e tumores maiores era a nefrectomia radical, porém essa técnica pode resultar em complicações como insuficiência renal crônica e comprometimento cardiovascular. Entretanto, atualmente, a nefrectomia parcial mostrou-se como uma opção relevante no tratamento de massas pequenas, além de apresentar-se como alternativa promissora para o manejo de tumores renais maiores (LI J, et al., 2019).

Pode-se concluir com o trabalho proposto que a colonoscopia é considerada um exame de rastreio excelente nos pacientes com pólipos não adenomatosos, adenomatosos e serrilhados. Com relação ao adenocarcinoma retal, a retossigmoidectomia é considerada um tratamento curativo eficaz. Contudo, a COVID-19 é um fator de risco para alta mortalidade em pacientes com câncer. Todavia, o caso em tela teve desfecho clínico favorável com cura do paciente para o coronavírus e para o CCR.

\section{REFERÊNCIAS}

1. ALDUBAYAN SH, et al. Inherited DNA-repair defects in colorectal cancer. The American Journal of Human Genetics, 2018; $102(3)$ : 401-414.

2. AMERICAN CANCER SOCIETY. Understanding Your Pathology Report: Colon Polyps (Sessile or Traditional Serrated Adenomas). Disponível em: https://www.cancer.org/treatment/understanding-yourdiagnosis/tests/understanding-your-pathology-report/colon-pathology/colon-polyps-sessile-or-traditional-serratedadenomas.html. 2017. Acesso em: 18 de setembro de 2020.

3. BICALHO LGMF, et al. Epidemiologia dos adenomas serrilhados em uma casuística do Hospital Alemão Oswaldo Cruz em São Paulo. GED gastroenterol. endosc. Dig. 2015: 34(3):101-106.

4. BRENNER $\mathrm{H}$, et al. Effect of screening sigmoidoscopy and screening colonoscopy on colorectal cancer incidence and mortality: systematic review and meta-analysis of randomised controlled trials and observational studies. Bmj, 2014; 348(g2467).

5. DE MENEZES CCS, et al. Câncer colorretal na população brasileira: taxa de mortalidade no período de 2005-2015. Revista Brasileira em Promoção da Saúde, 2016; 29(2): 172-179.

6. GUINNEY J, et al. The consensus molecular subtypes of colorectal cancer. Nature medicine, 2015; 21(11): 13501356, 2015.

7. JOFFRIN L, et al. Bat coronavirus phylogeography in the Western Indian Ocean. Scientific Reports | (2020) 10:6873.

8. LI J, et al. Partial nephrectomy versus radical nephrectomy for cT2 or greater renal tumors: a systematic review and meta-analysis.Minerva Urol Nefrol. 2019 Oct;71(5):435-444. Epub 2019 Jul 8.

9. MENEGASSI FGM, et al. Prognóstico do acidente vascular cerebral em paciente com SARS-CoV-2 e cirurgia de revascularização do miocárdio. Revista Eletrônica Acervo Saúde, 2020; 12(10): e5208.

10. NGUYEN LH, et al. Pathways of Colorectal Carcinogenesis. Journal Pre-proof. Gastroenterology. 2019. S00165085(19)41441-8.

11. PESTANA JSG, MARTINS SFF. Câncer colorretal: análise comparativa das características clínicas e anatomopatológicas em doentes com idade superior e inferior a 45 anos de idade e impacto no prognóstico. Journal of Coloproctology (Rio de Janeiro), 2016; 36(4): 196-202.

12. POPOUTCHI P. Conceitos em Carcinogênese Colorretal. Endoscopia Terapêutica. Med Idea. 2016.

13. SILVA AAM, et al. Neoplasias primárias sincrônicas: câncer colorretal e carcinoma de células renais. Jornal de Coloproctologia do Rio de Janeiro. 2017. Vol. 37. Núm. S1. Páginas 99. (Outubro 2017).

14. SINGH R, et al. Sessile serrated adenoma/polyps: Where are we at in 2016? World J Gastroenterol 2016 September $14 ; 22(34): 7754-7759$

15. SINGHAL T. A Review of Coronavirus Disease-2019 (COVID-19). Indian J Pediatr. 2020; 87(4):281-286. Epub 2020 Mar 13

16. SOARES A. Cytoreductive Nephrectomy for Metastatic Renal Cell Carcinoma: How to Apply New Evidence in Clinical Practice.Oncology. 2020;98(1):1-9. Epub 2019 Sep 12.

17. SZYLBERG L, et al. Serrated Polyps and Their Alternative Pathway to the Colorectal Cancer: A Systematic Review. Gastroenterology Research and Practice. Volume 2015, 573814, 7.

18. THANIKACHALAM K, KHAN G. Colorectal Cancer and Nutrition. Nutrients 2019; 11(1): 164.

19. WIELANDT AM, et al. Caracterización de pacientes con cáncer colorrectal esporádico basado en la nueva subclasificación molecular de consenso. Revista médica de Chile, 2017; 145(4): 419-430.

20. WORLD HEALTH ORGANIZATION. Coronavirus Disease (COVID-19) Dashboard. 2020. Disponível em: https://covid19.who.int. Acesso em: 30 de setembro de 2020. 